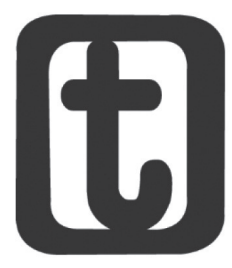

\title{
SERVIÇO SOCIAL, LUTAS FEMINISTAS E VIOLÊNCIA CONTRA A MULHER
}

\author{
SOCIAL SERVICE, FEMINIST STRUGGLES AND \\ VIOLENCE AGAINST WOMEN
}

\section{Fernanda Marques Queiroz ${ }^{1}$ Maria Ilidiana Diniz ${ }^{2}$}

\section{RESUMO}

O presente artigo trata da problemática da violência contra a mulher, historicizando sua visibilidade como um problema público, a partir das ações políticas do movimento feminista no final da década de 1970. Procura suscitar uma reflexão sobre a necessidade da articulação desse movimento com o Serviço Social, visto que a luta pela superação dessa violência demanda ações coletivas que tenham como norte a construção de uma nova ordem societária sem dominação-exploração de classe, raça/etnia e gênero, conforme preconiza o projeto ético-político da profissão. Nesse sentido, concluímos que o trabalho dos assistentes sociais é fundamental, tendo em vista sua capacidade teórico-metodológica, técnico-operativa e ético-política

1 Professora Adjunta da Faculdade de Serviço Social da Universidade do Estado do Rio Grande do Norte. Docente do Programa de Pós-Graduação em Serviço Social e Direitos Sociais da UERN. Atualmente cursa pós-doutorado na Université Paris VII- França. Pesquisadora do Grupo de Estudos e Pesquisas das Relações Sociais de Gênero e Feminismo (GEF) da UERN. E-mail: fernandamarquesdequeiroz@ gmail.com.

2 Doutoranda do Programa de Pós-Graduação em Serviço Social da Universidade do Estado do Rio de Janeiro. Atualmente cursa Doutorado Sanduíche na Université Paris VII. Pesquisadora do Grupo de Estudos e Pesquisas das Relações Sociais de Gênero e Feminismo (GEF) da UERN. E-mail: ilidianadiniz@gmail.com. 


\section{temporalis}

que viabiliza a formulação, implementação, monitoramento e avaliação de políticas públicas, visando a garantia de direitos.

Palavras-chave: Serviço Social. Lutas feministas. Violência contra a mulher.

\section{ABSTRACT}

This article deals with the problem of violence against women, historicizing its visibility as a public problem, from feminist movement political actions in the end of 1970s. It seeks to encourage a reflection on the need for articulation of this movement with Social Service, since the struggle for resilience of this violence demands collective actions that are guided by building a new society order without dominationexploration of class, race/ethnicity and gender, as advocates the ethicalpolitical project of the career. In this sense, we concluded that the work of social assistants is fundamental, given its methodological-theoretical, technical-operative and ethical-political capacity, which enables public policies formulation, implementation, monitoring and evaluation, aiming the guarantee of rights.

Keywords: Social Service. Feminist struggles. Violence against women.

Submetido em 01/02/2014

Aceito em 02/11/2014

\section{INTRODUÇÃO}

Vivemos em uma sociedade marcada pelas desigualdades socioeconômicas, pela mercantilização da vida social e pela dominação capitalista-patriarcal-racista. Nesse contexto, há um intenso agravamento das expressões da questão social e o afastamento do Estado de suas responsabilidades, transferindo-as para a sociedade civil.

Aliando-se a essas questões, acrescentem-se as problemáticas que particularizam as mulheres numa sociedade permeada pela cultura machista e sexista, cujas expressões se materializam a partir do controle da sua sexualidade, da exploração do erotismo, da mercantilização do corpo e, fundamentalmente, da persistência da violência perpetrada contra esse segmento ${ }^{3}$, cujos

3 Segundo pesquisa realizada pelo Serviço Social do Comércio (SESC) em parceria com a Fundação Perseu Abramo, intitulada "Mulheres brasileiras e gênero nos espaços públicos e privados", divulgada em 2011, a cada dois minutos cinco mulheres são agredidas violentamente no Brasil. Com base nas amostras, 
números no Brasil são bastante preocupantes, apesar da aprovação da Lei Maria da Penha.

A violência contra a mulher ${ }^{4}$ passa a ser reconhecida pelo Estado como um problema público, a partir do final da década de 1970. Essa temática é oriunda das mobilizações protagonizadas pelo movimento feminista ${ }^{5}$ que, inicialmente, esteve mais ligado à denúncia das violências e, num segundo momento, desenvolveu ações, visando garantir o atendimento e o apoio por meio de serviços específicos para essas mulheres, a exemplo da experiência dos SOS Mulher no Rio de Janeiro, Minas Gerais e São Paulo e das Delegacias Especializadas no Atendimento à Mulher (DEAMs) ${ }^{6}$ (QUEIROZ, 2008).

Na contemporaneidade, a violência contra a mulher é uma realidade bastante presente na vida das mulheres, constituindo-se em uma expressão da questão social7, a qual demanda inter-

os(as) pesquisadores apresentam a estimativa de que 7,2 milhões de mulheres com mais de 15 anos já sofreram agressões, 1,3 milhão delas nos doze meses que antecederam à pesquisa. O estudo traz ainda uma análise comparativa dos dez anos em relação à última pesquisa realizada em 2001. Naquela época, oito mulheres eram agredidas a cada dois minutos. Essa pequena redução do número de mulheres vitimadas pela violência entre os anos pesquisados pode ser atribuída, em parte, à sanção da Lei Maria da Penha, que, por si só, não tem sido suficiente para erradicar esse tipo de violência.

4 Atos que, pela ameaça ou força, são praticados contra as mulheres nos espaços privados ou públicos, bem como as agressões físicas, sexuais, morais, psicológicas e discriminações, visando intimidar, punir e humilhar, ferindo a integridade física e subjetiva das mulheres, constituindo-se numa violação de direitos humanos e num grave problema de saúde pública (QUEIROZ, 2008).

5 Nessa época, o slogan "Quem ama não mata" era emblemático das lutas pelo fim da violência contra as mulheres. O feminismo se constitui em um movimento social e político cuja ação objetiva a construção da igualdade entre homens e mulheres por meio do fortalecimento e organização política das mulheres, visando a sua autonomia, liberdade e emancipação, contribuindo para mudanças sociais, econômicas, políticas e culturais e, sobretudo, provocando mudanças de valores na sociedade. No entanto, não podemos falar em feminismo no singular, mas numa pluralidade de feminismos. Vale registrar aqui que coadunamos com as ideias do feminismo socialista, ou seja, comprometido com as lutas pela emancipação humana.

6 Criadas a partir de 1986, sendo o estado de São Paulo pioneiro.

7 “Diz respeito ao conjunto das expressões das desigualdades sociais engendradas na sociedade capitalista madura, impensáveis sem a intermediação do Estado. Tem sua gênese no caráter coletivo da produção, contraposto à apropriação privada da própria atividade humana o trabalho, das condições necessárias à sua realização, assim como de seus frutos" (IAMAMOTO, 2001, p. 10). 


\section{temporalis}

venção do Estado via políticas sociais públicas. Trata-se, pois, das desigualdades de gênero, raça e classe, portanto, um dos objetos sobre os quais incide o trabalho dos(as) assistentes sociais, configurando-se em "matéria-prima” de sua intervenção.

Ademais, o avanço da mundialização neoliberal repercute diretamente nas transformações do Serviço Social. A desresponsabilização do Estado em face da garantia dos direitos dos cidadãos traz repercussões nas relações de trabalho e nas profissões, exigindo redefinições em termos de competências frente às novas problemáticas que demandam o trabalho profissional (LISBOA; PINHEIRO, 2005, p. 203). Nesse cenário, a violência contra a mulher tornou-se cada vez mais visível e passou a ser discutida como um problema público a ser enfrentado.

Mediante esse novo quadro conjuntural, lamamoto (1999, p. 89) lembra que o momento presente desafia os(as) assistentes sociais a se qualificarem para acompanhar, atualizar e explicar as mudanças que ocorrem na realidade social. Entre as novas competências exigidas está, sobretudo, a produção de conhecimento acerca da complexa realidade em que cada profissional se insere em diferentes espaços sócio-ocupacionais, visando dar suporte a sua intervenção.

Dessa forma, seja no âmbito da violência contra a mulher, seja em qualquer outro processo da totalidade da vida social, os(as) assistentes sociais intervêm sobre as variadas expressões da questão social, isto é, sobre estas incide a ação profissional. Para tanto, é imprescindível o conhecimento da realidade em que atua, a fim de compreender como os sujeitos enfrentam as sequelas da questão social, a exemplo da problemática da violência contra a mulher, o que requer, como bem descreve Behring (2009, p. 276),

[...] o reconhecimento do indivíduo social com sua capacidade de resistência e conformismo frente às situações de opressão e de exploração vivenciadas; com suas buscas e iniciativas (individuais e/ou coletivas) para enfrentar adversidades; com seus sonhos e frustações diante das expectativas de empreender dias melhores. Trata-se, portanto, de 
pensarmos a vida e os indivíduos em suas relações concretas e densas de historicidade [...].

Nesse sentido, a apropriação das categorias relações sociais de gênero, patriarcado e raça pelos(as) profissionais de Serviço Social se faz necessária para uma apreensão crítica das relações sociais e suas múltiplas determinações para além das classes, pois a realidade sobre a qual os(as) assistentes sociais se debruçam é complexa e multifacetada, sendo necessário, portanto, desvendar seus vários determinantes.

A atuação do Serviço Social se insere no Estado enquanto espaço contraditório na mediação de interesses dos usuários(as) e dos empregadores no contexto de hegemonia do sistema capitalista-patriarcal-racista, no qual é colocado para os(as) assistentes sociais o desafio de estabelecer alianças com o projeto feminista de emancipação das mulheres em situação de violência, uma vez que os ideários feministas estão em consonância com o projeto ético-político-profissional materializado, dentre outros princípios, na "opção por um projeto profissional vinculado ao processo de construção de uma nova ordem societária, sem dominação-exploração de classe, etnia e gênero", conforme preconiza o Código de Ética Profissional dos Assistentes Sociais (CFESS - Código de Ética Profissional, 1993).

É importante ressaltar que a produção teórica acerca da violência contra a mulher no interior do Serviço Social é recente e ainda reduzida. Somente a partir dos anos $1990^{8}$ é que surgiram trabalhos abordando a intervenção dos(as) assistentes sociais nas políticas públicas de enfrentamento à violência contra a mulher, o que se constitui num enorme desafio, em virtude de essa forma de violência ser bastante incidente na vida de milhares

8 Segundo dados fornecidos por Inácio (2010), em artigo publicado nos anais do IX Seminário Internacional Fazendo Gênero, intitulado: A relação entre "Projeto Feminista Emancipatório" e Projeto Ético-Político do Serviço Social: repercussões no enfrentamento à violência contra as mulheres no Brasil, "foram analisadas as comunicações orais dos 5 últimos Congressos Brasileiros de Assistentes Sociais (CBAS), dos anos de 1995, 1998, 2001, 2004 e 2007, excluindo-se os trabalhos apresentados pela autora do referido artigo no XI CBAS (2004) e no XII CBAS (2007). Vale informar que no X Encontro Nacional de Pesquisadores em Serviço Social (ENPESS) de 2006 e na $19^{\text {a }}$ Conferência Mundial de Serviço Social em 2007 registra-se apenas uma comunicação oral em cada congresso, elaborada pela autora deste artigo". 


\section{temporalis}

de mulheres brasileiras e pelo fato de esse segmento se constituir na maioria dos usuários(as) do Serviço Social.

Os estudos e debates que envolvem a relação Serviço Social e Gênero demonstram, pois, uma série de desafios para o seu aprofundamento, sendo, portanto, a nosso ver, indispensável a incorporação das categorias gênero e patriarcado para o processo contínuo de afirmação de seu projeto ético-político-profissional.

Ademais, não se pode ignorar, tampouco desconsiderar, o fato de que no Brasil são praticados, em média, 5.664 feminicídios ${ }^{9}$ por ano, aproximadamente, 472 por mês, quase 16 por dia ou, ainda, um em cada hora, segundo dados do Instituto de Pesquisas Econômicas Aplicadas (IPEA) ${ }^{10}$ de 2013.

O Serviço Social, assim como outras categorias profissionais, é chamado a contribuir mediante seu trabalho nos diversos serviços que compõem a rede de enfrentamento à violência contra a mulher ${ }^{11}$ em vários espaços sócio-ocupacionais, tendo em vista que tal problemática demanda ações na esfera da prevenção e combate à violência materializada no sistema de garantia

9 São os assassinatos de mulheres decorrentes de conflitos de gênero, notadamente, pelo fato de serem mulheres. Tais crimes são geralmente perpetrados por homens, principalmente parceiros ou ex-parceiros, e decorrem de situações de agressões nos domicílios, ameaças ou intimidação, violência sexual ou situações nas quais a mulher tem menos poder ou menos recursos do que o homem. Os parceiros íntimos são os principais assassinos de mulheres. No Brasil, no período de 2001 a 2011, estima-se que ocorreram mais de 50 mil feminicídios, o que equivale a, aproximadamente, 5.000 mortes por ano (IPEA, 2013).

10 Para maior aprofundamento acerca desses dados, consultar o documento "Violência contra a mulher: feminicídios no Brasil". Disponível em: <http:// www.ipea.gov.br/portal/images/stories/PDFs/130925_sum_estudo_feminicidio_ leilagarcia>.

11 O conceito de rede de enfrentamento à violência contra as mulheres diz respeito à atuação articulada entre as instituições/serviços governamentais, não governamentais e a comunidade, visando ao desenvolvimento de estratégias efetivas de prevenção e de políticas que garantam o empoderamento e construção da autonomia das mulheres, os seus direitos humanos, a responsabilização dos agressores e a assistência qualificada às mulheres em situação de violência. Portanto, a rede de enfrentamento tem por objetivos efetivar os quatro eixos previstos na Política Nacional de Enfrentamento à Violência contra as Mulheres - combate, prevenção, assistência e garantia de direitos - e dar conta da complexidade do fenômeno da violência contra as mulheres (SECRETARIA DE POLÍTICA PARA AS MULHERES, 2011, p. 13). 
de direitos às mulheres previstos na Lei Maria da Penha nas áreas da assistência social, previdência, saúde, educação, emprego e renda etc., tendo em vista que tal violência é um fenômeno multidimensional.

\title{
O SISTEMA CAPITALISTA-PATRIARCAL COMO FUNDANTE DA OPRESSÃO/DOMINAÇÃO DAS MULHERES
}

No contexto da mundialização neoliberal, a luta pela ampliação de direitos, pela igualdade de gênero, de raça/etnia e de classe perde, cada vez mais, sentido para a lógica das saídas individuais pela via do mercado. Essa cultura sustenta a ideia da mercantilização dos direitos que se articula com a ideologia difundida pelo sistema patriarcal-capitalista, no qual as mulheres, pobres e negras, não devem ter direitos, sendo culpabilizadas por sua situação.

Os direitos sociais são construídos a partir das relações concretas e buscam responder às necessidades sociais historicamente produzidas pelas classes. Sua efetivação prática na sociedade capitalista depende da correlação de forças e das disputas ideológicas que são travadas em torno dos interesses em questão.

De acordo com Behring (2009, p. 279), no âmbito do pensamento crítico a luta por direitos é inaugurada

\begin{abstract}
[...] a partir do término da Segunda Guerra Mundial, sobretudo após as nefastas experiências do nazi-fascismo, do stalinismo e, mais adiante, a partir da década de 1960, com as ditaduras militares na América Latina, período em que movimentos sociais e diferentes sujeitos coletivos passam a defender e consolidar, em sua agenda política a cultura de defesa dos direitos. Posteriormente, são incluídas questões relacionadas às relações sociais de gênero; raça/etnia; orientação sexual, dentre outras.
\end{abstract}

Nesse contexto, a luta feminista pela ampliação e garantia dos direitos das mulheres é uma das formas de enfrentamento ao modelo neoliberal nas políticas públicas e ao pensamento cultural desse modelo e suas implicações políticas.

Apesar dos avanços, da equiparação entre homens e mulheres levada a efeito na Constituição Federal de 1988, a ideologia patriarcal ainda subsiste. É inegável que as mulheres 


\section{temporalis}

conquistaram alguns avanços no mercado de trabalho, na política, na esfera privada etc., contudo, a base material do patriarcado não foi destruída (SAFFIOTI, 2004, p. 25), pois sua inserção no mundo do trabalho e em outros espaços da vida social se dá de forma precarizada e subordinada aos homens, a exemplo das atividades desenvolvidas pelas mulheres, que ainda estão voltadas à dimensão da prestação de serviço a outrem, tendo um caráter complementar ao trabalho dos homens, pouco prestígio e aferindo baixa remuneração em relação ao trabalho masculino ${ }^{12}$.

No modelo de sociabilidade vigente, as mulheres são inferiorizadas, estando, em maioria, sujeitas aos desejos e vontades dos homens. Dessa forma, muitas delas abdicam de seus sonhos, interesses e desejos porque estes não condizem com as vontades de seus parceiros.

O sistema capitalista se apropria da subordinação das mulheres para obter mais lucro, pois, "sendo inferiores aos homens", estão mais sujeitas a receber baixos salários, aceitar trabalhos precarizados, sem garantias trabalhistas, além da desvalorização e invisibilidade do trabalho doméstico que, geralmente, é desenvolvido pelas mulheres.

O patriarcado é anterior ao sistema capitalista, contudo, esse sistema o mantém e acentua, ao longo da história, a opressão das mulheres e perpetua diversos preconceitos e discriminações contra esse segmento.

Corroboramos o pensamento de Hartmann (apud SAFIOTTI, 1979, p. 232), quando define patriarcado como um "[...] conjunto de relações sociais que tem uma base material e no qual há relações hierárquicas entre homens, e solidariedade entre eles, que os habilitam a controlar as mulheres. Patriarcado é, portanto, o sistema masculino de opressão das mulheres".

Camurça (2007, p. 20) aponta para a emergência de quatro mecanismos que fundamentam o sistema patriarcal de dominação das mulheres, mediante os quais ele está, sistematicamente,

12 No Brasil, as mulheres ainda recebem, em média, 30\% a menos do salário pago aos homens e representam, no mundo, 70\% dos pobres e $2 / 3$ dos analfabetos (Censo IBGE/2010). 
reinventando-se, reproduzindo-se e perdurando-se. O primeiro deles, a violência contra a mulher, é compreendido como uma das práticas mais antigas e usuais da dominação patriarcal, sendo, portanto, recorrente tanto nos espaços públicos quanto nos privados. O segundo mecanismo trata do domínio sobre o corpo das mulheres, expresso, fundamentalmente, na repressão sexual, a qual limita sua autodeterminação reprodutiva, mediante a criminalização do aborto, a expropriação mercantil do corpo e, ainda, por intermédio da exploração da imagem das mulheres pelo mercado. $O$ terceiro mecanismo se fundamenta na manutenção da dependência econômica das mulheres, instituída tanto na organização social do trabalho quanto na imposição do trabalho doméstico como atribuição exclusiva das mulheres, sobrecarregando-as. Por último, a autora aponta para a não participação das mulheres nos espaços de poder, permanecendo, ainda, a falta de estímulo à participação político-institucional das mulheres nesses espaços, como partidos e sindicatos, bem como nas direções de movimentos sociais.

Destarte, esses quatro mecanismos são, a nosso ver, estruturantes da dominação patriarcal, contribuindo, sobretudo, para trazer à reflexão os elementos imprescindíveis para assegurar a reinvenção do patriarcado como base fundante da dominação e exploração que, na atualidade, encontra assento nas desigualdades de gênero, de classe, de raça/etnia, dentre outras formas de opressão das mulheres.

Podemos afirmar, por meio dessas considerações, que a opressão patriarcal e a exploração efetivada pelo sistema capitalista estão intimamente imbricadas e, ao falarmos da subordinação das mulheres na atual sociedade, não há como deixar de mencioná-las.

Sendo assim, não podemos apreender as desigualdades de gênero de uma forma desarticulada da perspectiva da totalidade, ou seja, da materialidade concreta da sociedade capitalista-patriarcal-racista, visto que, apesar de a categoria gênero estar relacionada aos estereótipos atribuídos ao masculino e ao feminino, tais "características" são sustentadas e disseminadas pela 


\section{temporalis}

sociedade, sendo a violência contra a mulher a expressão máxima da "lógica patriarcal de gênero"13.

\section{OS DESAFIOS DA ATUAÇÃO DO SERVIÇO SOCIAL FRENTE À PROBLEMÁTICA DA VIOLÊNCIA CONTRA A MULHER}

As políticas sociais se constituem como um campo contraditório, pois, ao mesmo tempo que garantem o atendimento de necessidades concretas da população usuária, configuram-se como instrumento que assegura a reprodução do capital via garantia da força de trabalho, amenizando os conflitos de classe. Desse modo, configuram-se como respostas do Estado frente às demandas da sociedade, expondo suas necessidades e expressando seu poder de pressão no sentido de publicizar tais necessidades, ou seja, são estratégias criadas pelo Estado para amenizar as situações mais graves, de modo a impedir o desastre total do sistema capitalista (TONET, 2009).

As políticas sociais, nesse cenário, são caracterizadas como residuais, seletivas, focalizadas, com custo excessivo do trabalho e, de preferência, devem ser acessadas via mercado, transformando-se em serviços privados.

De acordo com Behring (2006, p. 9), “esse processo é mais intensivo na periferia do capitalismo, considerando os caminhos da política econômica e das relações sociais delineadas [...]”. Nessa perspectiva, os benefícios, os serviços e os programas sociais deixam de ser direitos sociais para se tornar direitos do consumidor.

Nessa perspectiva, as políticas sociais públicas sofrem diversos rebatimentos, pois sua garantia pelo Estado depende da correlação de forças entre capital e trabalho, e o atual contexto revela uma situação bastante desfavorável para a classe trabalhadora. O surgimento das políticas sociais públicas não decorre da benevolência do Estado e da burguesia, mas em virtude das lutas travadas pela classe trabalhadora na defesa da melhoria de suas condições de vida, salário, trabalho etc.

13 Expressão cunhada por Saffioti (2004), que se refere ao sistema de opressão e dominação ao qual as mulheres estão submetidas. 
O modo de produção capitalista propicia a emergência de tais políticas, visto que faz surgir um cenário marcado pela exploração do trabalho, pelo acirramento da pobreza e das más condições de sobrevivência da maioria da população. Esse contexto perverso provoca a mobilização dos(as) trabalhadores(as) em busca da intervenção do Estado na questão social.

Por resultar das lutas coletivas dos(as) trabalhadores(as), as políticas sociais são, no cenário contemporâneo, constantemente ameaçadas, numa dinâmica em que esses sujeitos encontram bastante dificuldades para se organizar, em decorrência, dentre outros motivos, do aumento do desemprego, da fragmentação da classe trabalhadora e da criminalização dos movimentos sociais.

Conforme Behring (2004, p. 12), em vez de avançarmos no campo da proteção social, continuamos tendo políticas sociais extremamente focalizadas, "implementadas segundo a lógica do contador, ou a do mercado, dada a forte ênfase aos programas de transferência de renda, em detrimento da lógica do direito e da seguridade social universalizada".

No cerne dessas expressões, a problemática da violência contra a mulher, especialmente nas últimas décadas, ganhou espaço nas discussões acadêmicas e, mais gerais, adentrou o campo da intervenção do Serviço Social, mediante o planejamento, a formulação e a execução de políticas públicas de prevenção e combate à violência contra a mulher nos diversos espaços sócio-ocupacionais em que se insere (INÁCIO, 2010, p. 4).

O Serviço Social tem reafirmado, ao longo dos últimos trinta anos, um compromisso com o processo de construção de uma nova ordem societária sem exploradores e explorados, defendendo princípios norteadores como: o reconhecimento da liberdade como valor ético-central; a defesa intransigente dos direitos humanos, a cidadania, a democracia, a equidade e a justiça social e o empenho para eliminar os diferentes preconceitos que ora vigoram e o compromisso com a qualidade dos serviços prestados pelos(as) assistentes sociais ${ }^{14}$.

14 Princípios preconizados pelo Código de Ética Profissional dos Assistentes 


\section{temporalis}

Todavia, essa tem sido uma tarefa árdua diante das inúmeras adversidades, advindas, sobretudo, da ofensiva neoliberal, que preconiza que o mercado deve assumir lugar de centralidade, recebendo atenção privilegiada, principalmente por parte do Estado, que, dentre outras estratégias ideológicas, vem sistematicamente desencadeando um processo de desmonte de garantias de direitos já conquistados, em especial no campo legal, exigindo da profissão a radicalização das lutas com vistas à garantia da "construção de uma nova ordem social, sem dominação e/ou exploração de classe, etnia e gênero" (NETTO, 1999, p. 104-105).

Do ponto de vista histórico, o Serviço Social caminhou paralelo às conquistas dos movimentos feministas, configurando-se como aliado em muitas lutas, principalmente no que se refere à garantia e à ampliação de direitos, buscando provocar mudanças sociais, com vistas à formulação e à implementação de políticas públicas específicas para as mulheres.

Não podemos esquecer que foi por intermédio das lutas feministas que a violência contra a mulher passou a ser reconhecida como inerente ao padrão das organizações desiguais de gênero, que, por sua vez, são tão estruturais quanto a divisão da sociedade em classes sociais, ou seja, o gênero, a classe e a raça/etnia são, igualmente, estruturantes das relações sociais (SAFIOTTI, 2004).

Advindas dessas lutas históricas do movimento feminista por políticas públicas, podemos citar a criação das Delegacias Especializadas no Atendimento às Mulheres (DEAMs), a partir de meados da década de 1980 até a aprovação, em 2006, da Lei Maria da Penha (Lei 11.340/06)

A Lei Maria da Penha se situa no campo dos direitos, trazendo inovações ao tratamento dado pela Justiça a essas mulheres, constituindo-se num importante instrumento para o

Sociais, aprovado em 1993.

15 O nome dessa Lei é uma homenagem à Maria da Penha Maia Fernandes, farmacêutica, cearense, sobrevivente de duas tentativas de homicídio cuja história tornou-se emblema da impunidade dos crimes de violência contra a mulher, tendo esperado 19 anos pela condenação de seu agressor. 
enfrentamento à violência contra a mulher, sobretudo, no espaço doméstico, sendo preciso, também, criar novas estratégias de luta para que esse marco legal encontre efetivação material na vida das mulheres.

Tal lei apresenta especificidades, visto que não preconiza apenas um aparato jurídico-legal, mas também prevê a criação de uma rede integrada de serviços socioassistenciais e de saúde para as mulheres em situação de violência, o que vem a reafirmar a importância da inserção dos(as) assistentes sociais na formulação e execução dessas políticas.

Vale salientar que apesar da importância inequívoca da Lei Maria da Penha para a prevenção e combate à violência contra a mulher, em recente estudo realizado pelo Instituto de Pesquisas Econômicas Aplicadas (IPEA), em 2013, que avaliou o impacto da Lei Maria da Penha sobre a mortalidade de mulheres por agressões, constatou-se que não houve impacto, ou seja, não houve redução das taxas anuais de feminicídio, pois, ao compararmos os períodos antes e depois da vigência da Lei, as taxas de feminicídio por 100 mil mulheres foram 5,28 no período 2001-2006 (anterior a Lei) e 5,22 em 2007-2011 (depois da Lei) ${ }^{16}$.

Tal estudo aponta um discreto decréscimo da taxa de feminicídio no ano 2007, imediatamente após a vigência da Lei, o que nos leva a refletir acerca do fato de que a lei, por si só, não foi capaz de solucionar ou sequer minimizar tais violências.

Um dos grandes desafios no enfrentamento da violência contra a mulher é a efetivação de uma rede de serviços que agregue os diferentes programas e projetos, consolidando uma política social de atendimento, uma vez que os serviços existentes ainda não conseguem atender as mulheres, de forma integral, nem efetivar mudanças nos valores sexistas que permeiam as relações sociais.

O atual contexto é bastante desafiador, porém compreendemos que a organização política das mulheres, aliada a outros

16 Pesquisa intitulada "Violência contra a mulher: feminicídios no Brasil”, realizada em 2013 e coordenada por Leila Posenato Garcia, técnica do Instituto de Pesquisa Econômica Aplicada-IPEA. Disponível em: <http://www.ipea.gov.br>. 


\section{temporalis}

sujeitos sociais em prol da expansão e universalização das políticas públicas, dentre eles, a categoria dos(as) assistentes sociais, pode provocar importantes mudanças na intervenção do Estado, no que tange às respostas às demandas da população, em especial, das mulheres em situação de violência.

Enfrentar esses desafios demanda dos(as) assistentes sociais a reafirmação cotidiana no seu exercício profissional, do seu compromisso com os valores ético-políticos defendidos no novo projeto profissional contra quaisquer tipos de preconceito, discriminação, exploração e opressão.

A Lei Maria da Penha possibilita limitar o poder dos homens sobre as mulheres, uma vez que um dos motivos que colaboram para a perpetuação da violência contra a mulher é a impunidade dos agressores. "A violência impune humilha as mulheres e destrói seu amor próprio” (FARIA; NOBRE, 1997, p. 19). A referida Lei cria ainda mecanismos para impedir o ciclo da violência contra a mulher, pois a vítima será ouvida, além de contar com o acompanhamento de defensor(a) e de receber proteção policial e da justiça, a qual deverá, de maneira imediata, implementar medidas protetivas de urgência.

\section{CONCLUSÃO}

O cenário atual, marcado pela retração do Estado nos investimentos sociais, faz surgir uma série de desafios para a materialização dos direitos sociais das mulheres em situação de violência. Nesse contexto, a Lei Maria da Penha passa a sofrer diversos rebatimentos, pois, para que possa ser efetivada, faz-se necessário que exista uma rede de políticas públicas que vise proteger as mulheres, a exemplo de serviços de assistência social, saúde, emprego e renda, segurança, justiça, dentre outros.

Nesse sentido, são fundamentais a ação política do movimento feminista e a intervenção dos(as) assistentes sociais comprometidos(as) com o projeto ético-político-profissional nos processos de reivindicação, planejamento e execução de políticas públicas de prevenção e combate a essa forma de violência. Levamos em consideração que a referida Lei estabelece ao Estado a responsabilidade de implementar tais políticas capazes 
de promover mudanças para a superação das desigualdades entre homens e mulheres, pois, sendo as mulheres oprimidas, historicamente, elas se tornam mais pauperizadas do que os homens.

Nesse âmbito, o Serviço Social cumpriria com seu compromisso ético-político preconizado em seu projeto profissional com a emancipação humana ${ }^{17}$ e contra toda forma de opressão, discriminação e violência.

No que diz respeito aos entraves para a efetivação da Lei Maria da Penha, na prática, essa implementação tem sido feita de maneira lenta e desigual no país. Enquanto existem estados que contam com casas-abrigo, centros de orientação e atendimento às vítimas e centros de recuperação dos agressores, há outros em que as mulheres agredidas são orientadas, na própria delegacia, a não prestarem queixa e a desistirem das denúncias, fato que se dá devido à falta de profissionais capacitados(as) para o atendimento às mulheres em situação de violência, além da própria precarização dos serviços públicos que impacta no atendimento a essas mulheres.

Para além das lutas contra a lógica patriarcal de gênero, o atual contexto demanda uma articulação em prol da superação da sociabilidade capitalista, pois, à medida que essa sociedade se perpetua, se intensificam a pobreza, a miséria, a exploração da força de trabalho e a opressão das mulheres.

Muitos desafios havemos de enfrentar até colhermos os frutos conquistados com a Lei Maria da Penha, entre eles, a expansão, a interiorização dos Juizados de Violência Doméstica e

17 Para Marx, a história da humanidade se divide em dois grandes períodos: a pré-história e a história propriamente dita. O primeiro vai dos primórdios da humanidade até a extinção das classes sociais. O segundo começaria com a extinção das classes sociais, com tudo o que elas significam, e abriria um novo período, radicalmente diferente, da autoconstrução humana. Por que Marx faz essa divisão? Porque entre esses períodos há uma diferença essencial. E essa diferença está exatamente na questão da liberdade. No primeiro, embora haja graus e formas diferentes de liberdade, seu grau máximo jamais pode ultrapassar o caráter Jurídico-político. Desse modo, ela é essencialmente parcial e limitada. No segundo, ela se apresenta sob uma forma real, integral e essencialmente ilimitada, ou seja, é uma forma de liberdade que expressa o homem como um ser integralmente livre. É a esse segundo período que Marx chama de comunismo, reino da liberdade e emancipação humana (TONET, 2005, p. 81). 


\section{tempordils}

Familiar contra a mulher, o funcionamento dos serviços em rede, a criação da equipe de atendimento multidisciplinar, a implementação de programas e ações nos planos governamentais, nas várias esferas de poder, além da urgente mudança de cultura e de valores sexistas dos(as) profissionais que trabalham nessa área e da sociedade com um todo.

\section{REFERÊNCIAS}

BEHRING, Elaine Rossetti. Políticas sociais no governo Lula: uma reflexão. Revista Inscrita, Brasília, ano VI, n. 9, 2004.

BEHRING, Elaine; BOSCHETTI, Ivanete. Política social: fundamentos e história. São Paulo: Cortez, 2006.

BRASIL. Lei 11.340/2006. Brasília: Senado Federal, 2006.

CAMURÇA, Sílvia. “Nós Mulheres” e nossa experiência comum. Cadernos de Crítica Feminista, Recife, ano I, n. 0, dez. 2007.

CONSELHO FEDERAL DE SERVIÇO SOCIAL. Código de Ética Profissional dos Assistentes Sociais. Brasília: CFESS, 1993.

COSTA, Ana Alice Alcântara. O Movimento Feminista no Brasil: dinâmicas de uma intervenção política. Disponível em: <www.unb. br/ih/his/gefem/labrys7/ liberdade/anaalice.htm>. Acesso em: 19. dez. 2013.

DIAS, Maria Berenice. A Lei Maria da Penha na justiça: a efetividade da Lei 11.340/2006 de combate à violência doméstica e familiar contra a mulher. São Paulo: Revista dos Tribunais, 2007.

DINIZ, M. I.; QUEIROZ, Fernanda Marques. A relação entre gênero, sexualidade e prostituição. Divers@!, Matinhos, v. 1, p. 01-16, 2008.

FARIA, Nalu; NOBRE, Miriam. Gênero e desigualdade. São Paulo: SOF, 1997. (Coleção Cadernos Sempre Viva).

IAMAMOTO, Marilda Villela. Renovação e conservadorismo no Serviço Social. São Paulo: Cortez, 1999. 
. A Questão Social no capitalismo. Temporalis/ABEPSS, Brasília, ano 2, n. 3, jan./jun. 2001.

- As Dimensões Ético-Políticas e Teórico-Metodológicas no Serviço Social Contemporâneo. In: MOTA, Ana Elizabete et al. (Org.). Serviço Social e Saúde: trabalho e formação profissional. 2. ed. São Paulo: OPAS/OMS/ Ministério da Saúde/ Cortez, 2007.

INÁCIO, Mirian de Oliveira. A relação entre "Projeto Feminista Emancipatório" e Projeto Ético-Político do Serviço Social: repercussões no enfrentamento à violência contra as mulheres no Brasil. In: SEMINÁRIO INTERNACIONAL FAZENDO GÊNERO, 9., Florianópolis, 2010.

INSTITUTO BRASILEIRO DE GEOGRAFIA E ESTATÍSTICA - IBGE. Censo demográfico de 2010. Brasília, 2010. Disponível em: <www. ibge.gov.br>. Acesso em: 10 jan. 2014.

INSTITUTO DE PESQUISA ECONÔMICA APLICADA - IPEA. Disponível em: <www.ipea.gov.br>. Acesso em: 10 de jan. 2014.

LISBOA, Teresa Kleba; PINHEIRO, Eliana Aparecida. A intervenção do Serviço Social junto à questão da violência contra a mulher. Revista Katálysis, Florianópolis, v. 08, n. 02, p. 199-210, jul./dez. 2005.

NETTO, José Paulo. A construção do projeto ético-político contemporâneo. In: Capacitação em Serviço Social e Política Social. Módulo 1. Brasília: CEAD/ABEPSS/CFESS, 1999.

SAFFIOTI, Heleieth I. B. Gênero, patriarcado e violência. São Paulo: Fundação Perseu Abramo, 2004.

SERVIÇO SOCIAL DO COMÉRCIO/FUNDAÇÃO PERSEU ABRAMO. Mulheres brasileiras e gênero nos espaços públicos e privados. Disponível em: <http://www.fpa.org.br/sites/default/files/pesquisaintegra.pdf>. Acesso em: 05 dez. 2013. 


\section{temporalis}

TONET, Ivo. Expressões socioculturais da crise capitalista na atualidade. In: Serviço Social, direitos sociais e competências profissionais. Brasília: CEAD/UNB/CFESS/ABEPSS, 2009.

. Educação, cidadania e emancipação humana. ljuí: Editora da Unijuí, 2005. (Coleção fronteiras da educação). 